\title{
Value of a centralised approach in the management of haematemesis and melaena: experience in a district general hospital
}

\author{
R A E Holman, M Davis, K R Gough, P Gartell, D C Britton, R B Smith
}

\begin{abstract}
All patients presenting with acute upper gastrointestinal bleeding between November 1986 and April 1988 were admitted to a centralised joint medical/surgical unit, with a policy of early clinical and endoscopic assessment and rapid surgical intervention in those at high risk. Of the 430 patients admitted $69.5 \%$ were over the age of 60 and $30 \%$ had significant additional medical conditions. $50 \cdot 4 \%$ were bleeding from peptic ulcers and one third had been taking non-steroidal anti-inflammatory agents. Fifty five patients underwent surgery, which in two thirds was carried out within 24 hours of admission, usually for continued bleeding. In patients with peptic ulcer the operation rate was $21.6 \%$. Overall mortality was $3.7 \%$, and in those with bleeding gastric or duodenal ulcers $5.5 \%$; surgical mortality in the later group was $15 \cdot 2 \%$. All patients who died had serious concomitant pathology and $87 \%$ were over 70 years of age. Adoption of a centralised approach to management of haematemasis and melaena is feasible in a District General Hospital and associated with an improved survival.
\end{abstract}

Bleeding from the upper gastrointestinal tract is a common medical emergency, but in spite of advances in techniques for diagnosis, resuscitation, and surgical and anaesthetic management, the overall mortality has remained constant over the past three decades at around $10 \% .^{1-6} \mathrm{We}$ analysed the mortality from upper gastrointestinal bleeding in patients admitted to the Royal United Hospital, Bath, in the years 1981 to 1985 and found rates of 10 to $12 \%$, comparable with the results from other non-specialised centres. ${ }^{478}$

A logical approach to management involves admission of patients to a central unit staffed by medical and surgical gastroenterologists to allow prompt resuscitation and evaluation. This, coupled with an aggressive surgical policy in those identified as being at high risk, has been shown to lead to a significant reduction in mortality. ${ }^{90}$ The feasibility of such an approach, however, outside a major teaching centre has been questioned. To address this problem we negotiated the agreement of our medical and surgical colleagues to test the applicability and value of such an approach in this district general hospital. In this paper we report the first 18 months experience of such a team approach and conclude that such a policy may readily be applied by adaptation of existing resources, and results in a significant reduction in mortality.
Methods

PATIENTS

All patients admitted to the Royal United Hospital with suspected upper gastrointestinal bleeding are admitted to an 11 bedded ward jointly managed by two physicians and two surgeons with a specialist interest in gastroenterology. Other patients with gastrointestinal problems deemed best managed jointly by physicians and surgeons, generally those with severe inflammatory bowel disease and patients receiving total parenteral nutrition, or short term admissions after oesophageal dilatation or palliative intubation for carcinoma are also accommodated in this unit. Twenty four hour consultant cover is available for clinical and endoscopic assessment, and for all management decisions. Patients with haematemesis and melaena are endoscoped within 24 hours of admission by an experienced endoscopist. A regular ward round at 830 am is conducted by a consultant gastroenterologist and the majority of endoscopic assessments are carried out after this in a room adjacent to the ward. The nursing staff rotate through the main endoscopy unit so that they are experienced in endoscopic techniques and the care of the instruments. During the day management is coordinated by one of the three house physicians attached to the medical gastroenterology unit; at night and at weekends the admitting house physician assumes this role.

All patients included in this series had suffered a significant upper gastrointestinal bleed, defined as: (1) a vomit in excess of an estimated $100 \mathrm{ml}$ fresh or altered blood or (2) a definite melaena stool as witnessed by the admitting doctor.

No exclusions have been made for age and all patients deemed unfit for surgery are included if the entry criteria were satisfied.

After initial clinical assessment, including identification of previous drug therapy, early endoscopy is performed. In patients with peptic ulceration a detailed visual assessment of the ulcer crater is made to document the presence of stigmata denoting an increased risk of rebleeding - that is, a visible, bleeding or non-bleeding vessel or an adherent clot in the ulcer base. ${ }^{11} 12$

Management policy is for early intervention in the over 60 s where mortality is highest and a more conservative approach in patients under this age. In the present series intervention is surgical in all cases. The indications for surgery are as follows: age over 60 - continuing bleeding with spurting vessel at endoscopy. One rebleed. Transfusion requirements greater than four 
TABLE I Age and sex of patients admitted with acute upper gastrointestinal bleeding

\begin{tabular}{llllllll}
\hline Age & $<30$ & $31-40$ & $41-50$ & $51-60$ & $61-70$ & $71-80$ & $>80$ \\
\hline Men $\mathrm{n}=227$ & 16 & 18 & 25 & 31 & 48 & 57 & 32 \\
Women $\mathrm{n}=203$ & 5 & 8 & 6 & 22 & 36 & 62 & 54 \\
\hline
\end{tabular}

units blood in 24 hours. Age under 60 - continuing bleeding with spurting vessel at endoscopy. One rebleed. Transfusion requirements greater than $8 \mathrm{U}$ of blood in 24 hours or greater than twelve units in 48 hours.

Operations are performed by a consultant, senior registrar or experienced registrar. Postoperatively patients are returned to the unit to allow collaborative management of coexisting medical problems and are returned to a general surgical ward when their condition is stable. Patients not requiring surgery are kept on the unit until stable and then discharged home or transferred to a general medical ward. All patients with peptic ulceration, erosions and oesophagitis are started on $\mathrm{H}_{2}$ receptor blockers; these are continued in the long term in patients over the age of 60 with bleeding peptic ulcers. Repeat endoscopy is performed in patients with gastric ulceration to monitor healing and for histological and cytological assessment.

Variceal bleeding is managed with pitressin, Sengstaken tube and early injection sclerotherapy.

Records of all patients were entered into a standardised database (DataEase, Sapphire Systems Ltd) on a Hewlett Packard Vectra Computer. Statistical analysis was by $\chi^{2}$ test.

\section{Results}

Between November 1986 and April 1988430 patients were admitted ( 227 men, 203 women) (Table I). $69.5 \%$ were over the age of 60 and $32 \%$ were over 80 years of age. $95 \cdot 8 \%$ of patients underwent endoscopy within 24 hours of admission; in 15 patients the procedure was delayed to allow resuscitation and three patients died before they could be adequately resuscitated.

\section{CAUSES OF BLEEDING}

Two hundred and seventeen patients had peptic ulcers, accounting for just over $50 \%$ of the total with gastric and duodenal ulceration being almost equally divided (Table II). Gastric or duodenal erosions accounted for just over one third of the total, whilst Mallory Weiss tears, oesophageal varices and gastric carcinoma comprised just over $8 \%$. In a further 30 patients bleeding was either from another source or no cause for the haemorrhage could be found.

USE OF ASPIRIN AND NON-STEROIDAL ANTI-INFLAMMATORY DRUGS

$34.6 \%$ of patients had taken aspirin or a nonaspirin non-steroidal anti-inflammatory drug (NASAID) in the week before admission and $84 \%$ of these were over the age of 60 (Table III). Use of NASAIDS was significantly more common in patients over the age of 60 while the reverse was the case for salicylate ingestion.

\section{OVERALL OUTCOME}

\section{Rebleeding}

Rebleeding occurred in 18 patients $(4 \cdot 2 \%)$; all but one of these had either peptic ulcers or oesophageal varices (Table IV). Surgery was necessary to treat rebleeding or continued bleeding in 46 of 218 patients with gastric or duodenal ulcers and two of 16 with oesophageal varices. In the latter group, haemorrhage was satisfactorily controlled in the remainder by injection sclerotherapy. No patient with gastric or duodenal erosions, oesophagitis or Mallory Weiss tear required surgery.

\section{Ulcer stigmata and rebleeding}

A major stigma (spurting vessel, visible vessel or adherent clot in ulcer base) was present in 66 patients (Table V). Twenty seven (40.1\%) required surgery to control continued bleeding or a recurrent haemorrhage compared with 19 of 141 without these stigmata $\left(\chi^{2}=35 \cdot 44\right.$, $\mathrm{p}=<0 \cdot 001)$

\section{Surgery}

Fifty five patients $(21 \cdot 7 \%)$ were operated on for continued or recurrent haemorrhage, 46 of these were for peptic ulcers (Table IV). Forty nine

TABLE II 430 admissions with upper gastrointestinal bleeding November 1986-April 1988

\begin{tabular}{lrr}
\hline Gastric ulcer & 109 & $(25 \cdot 3 \%)$ \\
Duodenal ulcer & 108 & $(25 \cdot 1 \%)$ \\
Gastric/duodenal erosions & 95 & $(22 \cdot 0 \%)$ \\
Oesophagitis & 52 & $(12 \cdot 1 \%)$ \\
Mallory Weiss & 16 & $(3 \cdot 7 \%)$ \\
Varices & 16 & $(3 \cdot 7 \%)$ \\
Gastric carcinoma & 4 & $(0 \cdot 9 \%)$ \\
Other, including no identifiable source & 30 & $(7 \cdot 0 \%)$
\end{tabular}

TABLE III Use of aspirin and NASAIDS in patients with peptic ulcer

\begin{tabular}{llll}
\hline Age & $<60$ & $>60$ & \\
\hline Salicylates & $n=42$ & $n=175$ & \\
NASAIDS & $8(19 \%)$ & $15(8 \cdot 6 \%)$ & $\mathrm{p}<0 \cdot 01$ \\
& $4(9 \cdot 5 \%)$ & $48(27 \cdot 4 \%)$ & $\mathrm{p}<0 \cdot 001$ \\
\hline
\end{tabular}

TABLE IV Rebleeding and surgery in 540 patients with acute upper gastrointestinal bleeding

\begin{tabular}{llll}
\hline Final diagnosis & Rebleed & No rebleed & Surgery \\
\hline Gastric/duodenal ulcer & 14 & 203 & 46 \\
Gastric/duodenal erosions & 1 & 94 & 0 \\
Oesophagitis & 0 & 52 & 0 \\
Mallory Weiss tear & 0 & 16 & 0 \\
Oesophageal varices & 3 & 13 & 3 \\
Gastric carcinoma & 0 & 4 & $2^{\star}$ \\
Other & 0 & 30 & 6 \\
\hline
\end{tabular}

$\star$ Neither operation for bleeding.

TABLE V Effect of ulcer stigmata on outcome

\begin{tabular}{ll}
\hline Stigma & $\begin{array}{l}\text { Rebled or continued } \\
\text { to bleed (surgery) }\end{array}$ \\
\hline Spurting vessel $n=15$ & $12(12)$ \\
Visible vessel $n=20$ & $4(4)$ \\
Adherent clot $n=31$ & $13(11)$ \\
Spots $n=10$ & $0(0)$ \\
None $n=141$ & $19(19)$ \\
\hline
\end{tabular}


TABLE VI Interval between admission and surgery $(h)$

\begin{tabular}{lclllll}
\hline & $0-12$ & $13-24$ & $25-48$ & $49-72$ & $73-96$ & $>96$ \\
\hline All patients & 10 & 25 & 8 & 2 & 2 & 8 \\
Gastric and duodenal ulcers & 8 & $22^{\star}$ & $7 \dagger$ & $1 \ddagger$ & $2 \ddagger$ & $6 \ddagger$ \\
\hline
\end{tabular}

$\star$ One for rebleeding; $†$ Four for rebleeding; $¥$ All for rebleeding.

\begin{tabular}{lc} 
TABLE VII Surgery in patients with upper gastrointestinal \\
bleeding & \\
\hline Gastric or duodenal ulcers & $26^{\star}$ \\
Vagotomy and pyloroplasty & 6 \\
Bilroth I & 5 \\
Polya & 5 \\
Oversew alone & 2 \\
Ulcer resection alone & 1 \\
Proximal gastrectomy & 1 \\
Total gastrectomy & \\
Varices & 1 \\
Gastroportal disconnection & 2 \\
Oversew of varices & 2 \\
Carcinoma & \\
Total gastrectomy & 1 \\
Other & 1 \\
Oversew duodenal fistula & 1 \\
Resection of ischaemic small bowel & 1 \\
Repair of aortoduodenal fistula & \\
Gastroenterostomy and insertion Celestin tube &
\end{tabular}

^Plus hemicolectomy for carcinoma of caecum in one.

TABLE VIII Mortality in patients with upper GI bleeding

\begin{tabular}{|c|c|c|c|c|c|}
\hline Age & $<=60$ & $61-70$ & $71-80$ & $>80$ & Total \\
\hline \multirow{2}{*}{$\begin{array}{l}\text { Overall } \\
\text { Peptic ulcer overall } \\
\text { Surgery overall } \\
\text { Surgery in gastric and } \\
\text { duodenal ulcer }\end{array}$} & $\begin{array}{l}1 / 131(0 \cdot 8 \%) \\
1 / 42(2 \cdot 3 \%) \\
1 / 6(16 \cdot 7 \%)^{\star}\end{array}$ & $\begin{array}{l}1 / 84(1 \cdot 3 \%) \\
1 / 48(2 \cdot 1 \%) \\
1 / 12(7 \cdot 6 \%)\end{array}$ & $\begin{array}{l}5 / 119(4 \cdot 2 \%) \\
4 / 66(6 \cdot 1 \%) \\
2 / 18(11 \cdot 1 \%)\end{array}$ & $\begin{array}{l}9 / 96(9 \cdot 5 \%) \\
6 / 61(9 \cdot 8 \%) \\
5 / 19(26 \cdot 3 \%)\end{array}$ & $\begin{array}{r}16 / 430(3 \cdot 7 \%) \\
12 / 217(5 \cdot 5 \%) \\
9 / 55(16 \cdot 4 \%)\end{array}$ \\
\hline & $1 / 5(20 \%)$ & $1 / 9(9 \cdot 1 \%)$ & $2 / 15(13 \cdot 3 \%)$ & $3 / 17(17 \cdot 6 \%)$ & $7 / 46(15 \cdot 2 \%)$ \\
\hline
\end{tabular}

^Also underwent hemicolectomy for carcinoma of caecum.

(89\%) of the patients were over the age of 60 . Two thirds of the operations were performed within 24 hours of admission, all but one for continued bleeding (Table VI). Surgery for bleeding gastric or duodenal ulcers carried out later than 24 hours after admission was for rebleeding in all but three cases. All patients fulfilling the criteria for surgery were operated on with the exception of three who were moribund on admission and who died shortly thereafter.
In patients with gastric or duodenal ulcer a vagotomy and pyloroplasty or partial gastrectomy was the most common operation (Table VII). In only seven was minimal surgery performed - that is, oversew or ulcer resection alone. One patient who had a vagotomy and pyloroplasty for a gastric ulcer with a clot in the base also underwent a right hemicolectomy for an unsuspected caecal carcinoma discovered at laparotomy.

Patients undergoing surgery stayed one to 27 days (median six days) in the unit whereas the corresponding figures for those treated medically was one to 17 days (median three days). Average bed occupancy throughout the period of study was $86 \%$.

\section{Mortality}

Sixteen patients died giving an overall mortality of $3 \cdot 7 \%$ (Table VIII). The mortality from peptic ulcers was $5.5 \%$ and in those undergoing surgery $15 \cdot 2 \%$. There was a progressive rise in mortality with increasing age; all but one of the patients who died were over the age of 60 and $87 \%$ were more than 70 years old. Table IX analyses the patients who died. All had serious concomitant pathology and three were admitted in a moribund state and died within a few hours of admission. A further patient found to have a gastric ulcer with no stigmata, deteriorated progressively after admission but on laparotomy was found to have total ischaemia of the small bowel and died on the operating table.

As well as increasing age and other medical problems, mortality was significantly higher in patients who rebled, who had a systolic blood pressure of $<=90 \mathrm{mmHg}$, or admission haemoglobin of $10 \mathrm{~g} / \mathrm{dl}$ or less on admission than in those without these complications (Table X).

\section{Discussion}

The proportion of patients presenting with upper gastrointestinal haemorrhage who are elderly has increased markedly over the past 30 years $^{378}$ and the advanced age of many of the

TABLE IX Analysis of deaths

\begin{tabular}{|c|c|c|c|c|c|}
\hline Age & Diagnosis & $\begin{array}{l}\text { Time to } \\
\text { surgery }(h)\end{array}$ & $\begin{array}{l}\text { Time to } \\
\text { death }(d)\end{array}$ & Other major pathology & Cause of death \\
\hline \multicolumn{6}{|c|}{ No surgery } \\
\hline 71 & Gastric ulcer & & 5 & Severe osteoarthritis & Bronchopneumonia \\
\hline 78 & Gastric ulcer & & 5 & Severe osteoarthritis & Bronchopneumonia \\
\hline 82 & Oesophagitis & & 4 & & $\begin{array}{l}\text { CVA following prolonged hypotension prior } \\
\text { to admission }\end{array}$ \\
\hline 83 & Duodenal ulcer & & 12 & Severe rheumatoid arthritis & Bronchopneumonia \\
\hline 85 & Oseophageal ulcer & & 1 & & $\begin{array}{l}\text { Shocked on admission. Never fully } \\
\text { resuscitated }\end{array}$ \\
\hline 86 & Duodenal ulcer & & 1 & Severe rheumatoid arthritis & $\begin{array}{l}\text { Shocked on admission, never fully } \\
\text { resuscitated }\end{array}$ \\
\hline 87 & Duodenal ulcer & & 1 & Severe rheumatoid arthritis & $\begin{array}{l}\text { Shocked on admission, never fully } \\
\text { resuscitated }\end{array}$ \\
\hline \multicolumn{6}{|c|}{ Surgery } \\
\hline 54 & Ğastric ulcer & 168 & 8 & $\begin{array}{l}\text { Ankylosing spondylitis. Ischaemic } \\
\text { heart disease. Carcinoma of } \\
\text { caecum }\end{array}$ & Bronchopneumonia \\
\hline 63 & Duodenal ulcer & 24 & 10 & & CVA after surgery \\
\hline 73 & Duodenal ulcer & 24 & 6 & & CVA after surgery \\
\hline 79 & Gastric ulcer & 24 & 25 & & Myocardial infarct. after surgery \\
\hline 80 & Aortoduodenal fistula & 12 & 7 & & Bronchopneumonia \\
\hline 82 & Gastric ulcer & 24 & 9 & Ischaemic small bowel resected & Bronchopneumonia \\
\hline 83 & Duodenal ulcer & 24 & 17 & $\begin{array}{l}\text { Severe chronic obstructive airways } \\
\text { disease on steroids }\end{array}$ & Bronchopneumonia \\
\hline $\begin{array}{l}84 \\
90\end{array}$ & Gastric ulcer & 12 & 2 & Recent myocardial infarct. & Congestive cardiac failure \\
\hline 90 & Gastric ulcer & 48 & 6 & Severe ischaemic heart disease & Congestive cardiac failure \\
\hline
\end{tabular}


TABLE X Mortality in relation to risk factors

\begin{tabular}{lcl}
\hline Risk factor & Deaths & \\
\hline Rebleeding $(\mathrm{n}=19)$ & $3(16-7 \%)$ & $\mathrm{p}<0.001$ \\
No rebleeding $(\mathrm{n}=411)$ & $13(3 \cdot 2 \%)$ & \\
Systolic BP $<=90(\mathrm{n}=27)$ & $6(22 \cdot 2 \%)$ & $\mathrm{p}<0.001$ \\
Systolic BP $>90(\mathrm{n}=403)$ & $10(2 \cdot 5 \%)$ & \\
$\mathrm{Hb}<=10(\mathrm{n}=199)$ & $11(5 \cdot 5 \%)$ & $\mathrm{p}<0.001$ \\
$\mathrm{Hb}>10(\mathrm{n}=231)$ & $4(1.73 \%)$ & \\
Age $>60(\mathrm{n}=299)$ & $15(5 \%)$ & $\mathrm{p}<0.005$ \\
Age $<=60(\mathrm{n}=131)$ & $1(0 \cdot 8 \%)$ & \\
Other medical problems $(\mathrm{n}=129)$ & $8(6.2 \%)$ & $\mathrm{p}<0.005$ \\
No other medical problems $(\mathrm{n}=301)$ & $8(2.6 \%)$ & \\
\hline
\end{tabular}

patients in the present series reflects this national trend. Increasing use of non-steroidal antiinflammatory drugs in patients over the age of 60 in an important contributory factor. One third of our patients with peptic ulcer had been taking these agents before admission and over $80 \%$ of these were over the age of 60 which is a similar proportion to that reported elsewhere. ${ }^{13}$

Upper gastrointestinal haemorrhage in the elderly carries a high mortality; there is often significant coexisting pathology, as shown in the present series and blood loss is poorly tolerated. Rebleeding or continued bleeding are important additional risk factors and up to $30 \%$ of such patients may die. ${ }^{214}$ Effective management of patients with upper gastrointestinal bleeding centres around balancing the risks of rebleeding against the hazards of surgery in elderly, debilitated patients; surgical mortality rates of up to $50 \%$ have been described in this situation. A policy of indiscriminate early surgery has been shown to convey no survival benefit over medical management alone; ${ }^{16}$ the proportion dying from complications of surgery was similar to the proportion who were treated medically and who died from the complications of continued or recurrent bleeding. ${ }^{17}$ Surgery must therefore be reserved for those who are more likely to die if nothing is done. Such a policy can only be effectively applied if all patients are admitted to a central unit staffed by physicians and surgeons with special expertise in gastroenterology; not only does this allow rapid assessment and resuscitation but also close monitoring by nursing staff acquainted with the particular problems likely to be encountered.

The results of the present series confirms the value of such an approach. Our overall mortality rate of $3 \cdot 7 \%$ is significantly lower than the figures of $15 \cdot 1 \%$ and $11 \cdot 7 \%$ reported in recently published series from district general hospitals in the United Kingdom..$^{78}$ The proportion of patients with peptic ulceration and oesophageal varices, who are most prone to rebleeding and in whom the mortality is highest, was similar in these two series to ours. Our mortality rate also compares favourably with the figure of $2 \cdot 7 \%$ reported by Hunt $e t a l^{9}$ whose policy was similar to our own. These workers did not report the ages of their patients but in a more detailed study describing the outcome of patients with duodenal ulcer ${ }^{18}$ ages were younger than in the present series. Our management policy was based on that described by Morris $e t a l^{10}$ who reported an overall mortality of $2 \%$ in patients with bleeding peptic ulcers undergoing early surgery. The mortality in our patients with gastric and duodenal ulcers was higher, but Morris et al did not include those deemed unfit for surgery, whilst in the present series there were no exclusions if the entry criteria were met.

Our operation rate in peptic ulcers is similar to that reported by Morris et $a l^{10}$ and nearly two thirds of our patients who underwent surgery were operated on within 24 hours of admission; the main indication was for continued bleeding. The value of identifying an actively bleeding vessel, a visible vessel or a clot in the ulcer base as a likely indicator of rebleeding ${ }^{11} 12$ is emphasised in the present series but over half of our patients with such stigmata settled spontaneously. Similarly nine of the 14 patients who rebled and subsequently required surgery had no such ulcer stigmata (Table V) and this emphasises the need for close monitoring of all patients by experienced medical and nursing staff. The value of this approach is shown in our low rate of rebleeding in patients with peptic ulceration $(6.4 \%)$ which is considerably lower than the figures $^{7 \text { 14 }_{15}}$ reported in other series. Such a policy of close monitoring also improves survival in high risk patients; mortality was higher in those with recognised risk factors including increasing age, rebleeding, hypotension or anaemia on presentation but was lower than in corresponding patients reported by other workers not using a centralised team approach to the problem. ${ }^{278}$

Intervention for patients with recurrent or continued bleeding in the present series was surgical in all cases. Medical treatment, with $\mathrm{H}_{2}$ receptor blockers or tranexamic acid ${ }^{19-22}$ had made little impact but endoscopic techniques for haematemesis with the laser, the heater probe or injection of adrenalin into the ulcer base $\mathrm{e}^{23-25}$ have produced promising results and may help to reduce mortality in the future. Up to one third of bleeding peptic ulcers, however, are unsuitable for such therapies either because they are endoscopically inaccessible or because bleeding is from a major vessel as the gastroduodenal artery. In such cases serious consideration must be given to limiting the procedure to that necessary to achieve haemastasis and avoiding major resectional procedures, particularly in the elderly. Patients can thereafter be maintained on $\mathrm{H}_{2}$ receptor blockers or other antiulcer agents to minimise the chance of recurrence. Wheatley et al adopted a policy of non-resectional surgery wherever possible and reported a surgical mortality of $4 \% .^{26}$

Various objections have been raised to the implementation of a centralised policy for management of upper gastrointestinal bleeding. Consultant colleagues may be reluctant to hand over the management of their patients through fear of depriving their junior staff of clinical experience. We have found that any such reservations are outweighed by the educational benefit of observing coordinated care, and in our hospital the nature of the junior staff rota ensures active involvement with specialist senior cover. The approach is very similar to that in a coronary care unit. The policy requires active consultant cover, but with the application of a standard protocol, together with a regular morning ward round, 'out of hours' callouts are rarely neces- 
sary, although a commitment to weekend cover is obviously needed.

Provision of the necessary resources in the face of financial constraints is obviously a potential problem. The key to successful management is admission of all patients to a single identifiable ward, and although a joint medical/surgical ward is desirable, it is not essential. Nursing expertise is central to the success of such a policy, but with a standardised protocol this is not difficult to implement and the same results should be achievable by reserving beds for patients with haematemesis and melaena on a specific ward. Our 11 bedded unit catered satisfactorily for a catchment population of 410000 and no patient requiring admission had to be turned away. The current practice of admitting these patients to medical rather than surgical beds is appropriate because of the high proportion with significant additional pathology. The other advantage of a centralised approach is that patients with minor lesions can rapidly be discharged.

We conclude that it is possible to apply a policy of centralised management for patients with haematemesis and melaena in a district general hospital by adaptation of existing resources, and this leads to benefits for patients, junior staff training, and utilisation of beds.

We are indebted to the staff of Stanley Wills Ward and the Endoscopy Unit for their enthusiasm and assistance, and to Joy Pollard for her help in collating the data. The provision computer equipment by Glaxo UK is gratefully acknowledged.

1 Avery-Jones F. Haematemesis and melaena with special reference to causation and to the factors influencing the mortality from bleeding peptic ulcers. Gastroenterology 1956 30: $166-90$.

2 Schiller KFR, Truelove SC, Gwyn Williams D. Haematemesis and melaena with special reference to factors influencing the outcome. BrMed $\mathcal{F} 1970 ; 2: 7-14$.

3 Allan R, Dykes P. A study of the factors influencing mortality rates from gastrointestinal haemorrhage. $Q \mathcal{F} M e d 1976 ; 45$. 533-50.

4 Johnston SJ, Jones PF, Kyle J, Needham CD. Epidemiology and course of gastrointestinal haemorrhage in northeast Scotland. BrMed F 1973; 3: 655-60.

5 Morgan AG, McAdam WAF, Walmsley GL, et al. Clinical findings, early endoscopy and multivariate analysis in patients bleeding from the upper gastrointestinal tract. prMed F 1977; ii: $237-40$.
6 Silverstein FE, Gilbert DA, Tredesco FJ, et al. The national ASGE survey on upper gastrointestinal bleeding. GSGE survey on upper gastroin

7 Madden MV, Griffith GH. Management of upper gastrointestinal bleeding in a district general hospital. $\mathcal{F} \mathrm{R}$ Coll intestinal bleeding in a district gent

8 Clason AE, Macleod DAD, Elton RA. Clinical factors in the prediction of further haemorrhage or mortality in acute upper gastrointestinal haemorrhage. Br $\mathcal{F}$ Surg 1986; 73: 985-7.

9 Hunt PS, Hansky J, Korman MG. Mortality in patients with haematemesis and melaena; a prospective study. $\mathrm{Br} \mathrm{Med} \mathcal{F}$ $1979 ; 1: 1238-40$.

10 Morris DL, Hawker PC, Brearly S, Simms M, Dykes PW, Keighley MRB. Optimal timing of operation for bleeding peptic ulcer: prospective randomised trial. $\mathrm{Br} \mathrm{Med} \mathcal{F} 1984$; 288: 1277-80.

11 Foster DN, Miloszewski KJA, Losowsky MS. Stigmata of recent haemorrhage in diagnosis and prognosis of upper recent haemorrhage in diagnosis and prognosis of

12 Storey DW, Bown SG, Swain CP, Salmon PR, Kirkham JS, Northfield TC. Endoscopic prediction of recurrent bleeding in peptic ulcers. $N$ Engl f Med 1981; 305: 915-6.

13 Somerville $K$, Faulkner G, Langman $M$. Non-steroidal antiinflammatory drugs and bleeding peptic ulcer. Lancet 1986; i: $462-4$

14 De Dombal FT, Clarke IR, Clamp SE, Malizia G, Kotwal MR, Morgan AG. Prognostic factors in upper gastrointestinal bleeding. Endoscopy 1986: 18 [suppl 2]: 6-10.

15 Jones PF, Johnston SJ, McEwan AB, Kyle J, Needham CD. Further haemorrhage after admission to hospital for gastrointestinal haemorrhage. $B r$ Med $\mathcal{F} 1973 ; 3: 660-4$.

16 Dronfield MW, Atkinson M, Langman MJS. Effect of different operation policies on mortality from bleeding peptic ulcer. $\operatorname{BrMed} \mathcal{F} 1979$; i: $1126-8$.

17 Vellacott KD, Dronfield MW, Atkinson M, Langman MJS. Comparison of surgical and medical management of bleeding peptic ulcers. $\operatorname{BrMed~} \mathcal{7} 1982 ; 1: 548-50$.

18 Hunt PS, Korman MG, Hansky J, Marshall RD, Peck GS, McCann WJ. Bleeding duodenal ulcer: reduction in mortality with a planned approach. $B r \mathcal{F}$ Surg $1979 ; 66$ : 633-5.

19 Collins R, Langman $M$. Treatment with histamine $\mathrm{H}_{2}$ antagonists in acute upper gastrointestinal haemorrhage. Implications or randomized trials. N Engl f Med 1985; 313 : 660-6.

20 Barer D, Ogilvie A, Henry D, et al. Cimetidine and tranexamic acid in the treatment of acute upper gastrointestinal bleeding. N Engl ₹ Med 1983; 308: 1571-5.

21 Stael von Holstein CCS, Eriksson SBS, Kallen R. Tranexamic acid as an aid to reducing blood transfusion requirements in acid as an aid to reducing blood transfusion requirements in

22 Biggs JC, Hugh TB, Dodds AJ. Tranexamic acid and upper gastrointestinal haemorrhage - a double blind trial. Gut gastrointestinal hat

23 Swain CP, Kirkham JS, Salmon PR, Bown SG, Northfield TC. Controlled trial of Nd-YAG laser photocoagulation in bleeding peptic ulcers. Lancet 1986; i: 1113-6.

24 Rutgeerts P, Vantrappen G, Van Hootegem $\mathrm{Ph}$, et al. Neodymium-YAG laser photocoagulation versus multipolar electrocoagulation for the treatment of severely bleeding ulcers: a randomized comparison. Gastrointest Endosc 1987; 33: 199-202.

25 Chung SCS, Leung JWC, Steel RJC, Crofts TJ, Li AKC. Endoscopic injection of adrenaline for actively bleeding ulcers: a randomized trial. BrMed F 1988; 296: 1631-3.

26 Wheatley KE, Dykes PW, Keighley MRB. Effect of a defined policy on the outcome of bleeding peptic ulcer disease policy on the outcome of bleedin
[Abstract]. Gut 1988; 29: A1472. 